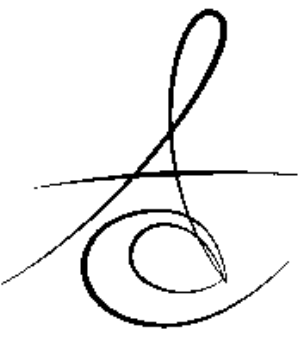

\title{
FARKLI GEÇİCI MATERYALLERİN FARKLI SIVILARDA KISA DÖNEM BEKLETME SONRASI RENK VE YÜZEY PÜRÜZLÜLÜK DEĞİŞİMİNİN İNCELENMESİ
}

\section{INVESTIGATION OF THE COLOR AND SURFACE ROUGHNESS CHANGES OF DIFFERENT TEMPORARY MATERIALS AFTER SHORT-TERM STORAGE IN DIFFERENT LIQUIDS}

\author{
Dr. Öğr. Üyesi M.Gülce SUBAŞI* \\ Uzm Dr. Muhammet KARCI***
}

\author{
Dr. Öğr. Üyesi Necla DEMİR ${ }^{* *}$ \\ Uzm Dr. Mehtap GÖKKAYA BOZKURT ${ }^{* * * *}$
}

Makale Kodu/Article code: 3526

Makale Gönderilme tarihi: 18.12.2017

Kabul Tarihi: 19.04.2018

\section{ÖZET}

Amaç: Dört farklı geçici materyalin 3 farklı sıvıda kısa dönem bekletme sonunda renk ve yüzey pürüzlülük değişiminin incelenmesidir.

Gereç ve Yöntem: Bu çalışmada disk şeklinde 4 farklı geçici materyal (Whitepeaks CopraTemp, Integra, Triad, Systemp.c\&b II) (renk: A2) kullanıld $(n=15)$. Hazırlanan materyaller $37^{\circ} \mathrm{C}$ 'deki distile suda 24 saat süre bekletildikten sonra, tüm örneklerin başlangıç renk ve yüzey pürüzlülük değerleri ölçüldü. Her bir geçici materyal daha sonra bekletilecek SIVı tipine göre 3 alt gruba (distile su (kontrol), çay, kahve) ayrıldı $(n=5)$. Örnekler $37^{\circ} \mathrm{C}^{\prime}$ deki ilgili sıvılarda 48 saat süre bekletildikten sonra, tüm örneklerin renk ve yüzey pürüzlülük değerleri tekrar ölçüldü. Materyallerin 48 saat sonraki renk değişim değerleri iki yönlü varyans analizi (ANOVA) ile incelendi. Başlangıç yüzey pürüzlülük değerleri tek yönlü ANOVA ile incelendi. Kırk sekiz saat bekletme sonrası yüzey pürüzlülük değerleri ve yüzey pürüzlülük fark değerleri iki yönlü ANOVA ile incelendi $(p=0,05)$.

Bulgular: Geçici materyallerin 48 saat sonraki renk değişimini sadece sıvı tipi anlamlı olarak etkilemiştir $(p=0,000)$. Yüzey pürüzlülük fark değerleri materyal ve sıvı tipi etkileşiminden etkilenmiştir $(p=0,001)$. Bilgisayar destekli tasarım ve üretim sistemi (CAD/CAM) ile üretilen geçici materyal (Whitepeaks CopraTemp), diğer geçici materyaller ile karşılaştırıldığında en az pürüzlülük değişim değeri göstermiştir $(p \leq 0,005)$.

Sonuç: Geçici materyallerin renk ve yüzey pürüzlülük değişim sonuçları beraber değerlendirildiğinde, CAD/CAM sistemi ile üretilen geçici materyal diğer geçici materyallere göre tercih edilebilir.

Anahtar Kelimeler: Geçici diş restorasyonları, Renk, Yüzey özellikleri

\section{ABSTRACT}

Aim: To investigate the color and surface roughness changes of 4 different temporary materials after shortterm storage in 3 different liquids.

Material and Methods: In this study, disk shaped 4 different temporary materials (Whitepeaks Copra Temp, Integra, Triad, Systemp.c\&b II) (color: A2) were used $(n=15)$. After the prepared materials were stored in distilled water at $37^{\circ} \mathrm{C}$ for 24 hours, all specimens initial color and roughness values were measured. Then, each temporary material was divided into 3 subgroups (distilled water (control), tea, coffee) according to liquid type to be stored $(n=5)$. After the specimens were stored in respective liquids at $37^{\circ} \mathrm{C}$ for 48 hours, the color and roughness data of all specimens were measured again. The color change values of materials after 48 hours were analysed by two-way analysis of variance (ANOVA). Initial surface roughness values were analysed by one-way ANOVA. Surface roughness values after 48 hours storage and the surface roughness difference values were analysed by two-way ANOVA $(p=0,05)$.

Results: Only liquid type significantly affected the color change of temporary materials after 48 hours $(p=0,000)$. Surface roughness difference values were affected by material and liquid type interaction $(p=0,001)$. The temporary material (Whitepeaks CopraTemp) produced by computer aided design and computer aided manufacturing system (CAD/CAM) presented the lowest roughness change value as compared to the other temporary materials $(p \leq 0,005)$. Conclusion: If the color and surface roughness change results of temporary materials were evaluated together, the temporary material produced with CAD/CAM system can be preferred instead of other temporary materials.

Keywords: Temporary dental restorations, Color, Surface properties

\footnotetext{
Kütahya Sağlık Bilimleri Üniversitesi Diş Hekimliği Fakültesi Protetik Diş Tedavisi ABD, Kütahya

${ }^{* *}$ Selçuk Üniversitesi Diş Hekimliği Fakültesi Protetik Diş Tedavisi ABD, Konya

***Alanya Ağız ve Diş Sağlığı Merkezi, Alanya

*** Serbest uzman diş hekimi, Adapazarı

${ }^{*} \neq$ Bu çalışma 21. Uluslararası Estetik Diş Hekimliği Kongresi’nde (13-15 Ekim 2017, İstanbul) 


\section{GÍRİş}

Geçici restorasyonlar protetik tedavide diş preparasyonu sonrasında sonuç restorasyonun dişe daimi simante edilmesine kadar olan süreçte geçici görev gören ve yapılan restorasyon tipine göre birkaç gün ile birkaç hafta süre ile kullanılan restorasyonlardır. ${ }^{1,2}$

Günümüzde geçici restorasyon yapımında polimetilmetakrilat (PMMA), polietilmetakrilat (PEMA), polivinil metakrilat (PVMA), Işıkla polimerize üretan dimetakrilat (UDMA), bisakril kompozit rezin (Bis-GMA) ve mikrodolduruculu kompozit rezin vb. gibi farklı içeriğe sahip materyaller kullanılmaktadır. ${ }^{1,3-5}$

Geçici restorasyonlar ağız içinde direk veya ağız dışında model üzerinde indirek olarak hazırlanabilirler. İndirek teknik direk tekniğe göre netlik açısından tercih edilmektedir. ${ }^{3}$ İlave olarak son yıllarda bilgisayar destekli tasarım/bilgisayar destekli kazıma (CAD/CAM) teknolojisi daimi restorasyon yapımında olduğu gibi, geçici restorasyon yapımında da kullanılmaktadır. ${ }^{6}$ CAD/CAM tekniği ile geçici yapımında optik ölçü alınması ve bu teknikte hazır geçici blokların kullanılması bu tekniğin avantajını oluşturmaktadır. ${ }^{6}$

Geçici restorasyonların başarılı olabilmesi için biyolojik, mekanik ve estetik gereksinimleri yerine getirebilmesi gereklidir. ${ }^{7}$ Sabit protetik tedavide uzun dönemli tedavilerde özellikle ön bölgede geçici restorasyonun renk stabilitesi önem arz etmektedir. ${ }^{8}$ Sabit protezlerde geçici restorasyonların renklenmesi hasta memnuniyetsizliğine ve yenileme gerektiğinde ekstra masrafa neden olmaktadır. ${ }^{9}$ Bu nedenle, renk stabilitesi geçici restorasyon materyalini seçerken önemli bir kriterdir. ${ }^{9-12}$ İlave olarak seçilecek olan geçici materyalin yüzey düzgünlüğü de renk stabilitesi kadar klinik önem arz etmektedir. ${ }^{13}$

Yapılan çalışmalar farklı içeceklerin geçici akrilik materyallerin renklenmesi üzerindeki etkisi ${ }^{8,11,14}$ veya farklı sıvıların geçici akrilik materyallerin yüzey pürüzlülük değişimi üzerindeki etkisinin ${ }^{13}$ incelenmesi ile sınırlı kalmıştır. Ticari olarak bulunan farklı yapıdaki geçici materyallerin her birinin birbirine göre farklı avantaj ve dezavantajları bulunmaktadır. Farklı geçici materyallerin renk stabilite ve pürüzlülüklerini birlikte inceleyen bir çalışma bulunmamaktadır.

$\mathrm{Bu}$ in vitro çalışmanın amacı 4 farklı geçici materyalin (ışıkla polimerize, otopolimerize, kimyasal polimerize ve CAD/CAM) farklı tip sıvılarda (distile su, çay, kahve) kısa dönem (48 saat) bekletme sonrası renk ve yüzey pürüzlülük değişimlerinin incelenmesidir.

Test edilen hipotezler

1. Tüm materyallerin 48 saat sonraki renk değişim değerleri materyal ve sıvı tipinden etkilenmemiştir.

2. Tüm materyallerin başlangıç yüzey pürüzlülük değerleri materyal tipinden etkilenmemiştir.

3. Tüm materyallerin 48 saat sonraki yüzey pürüzlülük değerleri materyal tipi ve sıvı tipinden etkilenmemiştir.

\section{GEREÇ VE YÖNTEM}

$\mathrm{Bu}$ çalışmada sabit protetik tedavide geçici yapımında kullanılan 4 farklı materyal (Triad, Whitepeaks CopraTemp, Integra, Systemp.c\&b II) kulla nılmıştır. Çalışmada kullanılan materyallerin içerik ve lot numaraları Tablo 1'de verilmiştir. Her bir materyalden üretici firma önerileri doğrultusunda özel bir teflon kalıp aracılığı (Resim 1) ile disk şeklinde (10 $\mathrm{mm}$ çap, $3 \mathrm{~mm}$ yükseklik) standardize örnekler hazırlanmıştır $(n=15)$.

Tablo 1. Çalışmada kullanılan geçici materyaller.

\begin{tabular}{ccccc}
\hline Materyal & İçerik & Üretici Firma & $\begin{array}{c}\text { Lot } \\
\text { numara }\end{array}$ & Renk \\
\hline $\begin{array}{c}\text { Whitepeaks } \\
\text { CopraTemp }\end{array}$ & $\begin{array}{c}\text { Polimetilmetakrilat } \\
\text { (PMMA) içerikli } \\
\text { CAD/CAM blok }\end{array}$ & $\begin{array}{c}\text { Ivoclar } \\
\text { Vivadent, } \\
\text { Schaan, } \\
\text { Liechtenstein }\end{array}$ & P10374 & A2 \\
\hline $\begin{array}{c}\text { Integra } \\
\text { (Otopolimerizan) }\end{array}$ & $\begin{array}{c}\text { Polimetilmetakrilat } \\
\text { (PMMA) içerikli } \\
\text { akrilik rezin }\end{array}$ & $\begin{array}{c}\text { Birleşik Grup } \\
\text { Dental, } \\
\text { Ankara, } \\
\text { Türkiye }\end{array}$ & 160614 & A2 \\
\hline $\begin{array}{c}\text { Triad } \\
\text { (Işık ile }\end{array}$ & $\begin{array}{c}\text { Üretan dimetakrilat } \\
\text { (UDMA) içerikli } \\
\text { kompozit rezin }\end{array}$ & $\begin{array}{c}\text { Dentsply, } \\
\text { York, ABD }\end{array}$ & $150903 \mathrm{~A}$ & $\mathrm{~A} 2$ \\
\hline $\begin{array}{c}\text { Systemp.c\&b II } \\
\text { (Kimyasal olarak } \\
\text { polimerize) }\end{array}$ & $\begin{array}{c}\text { dimetakrilat, } \\
\text { etoksilat (Bis-EMA) } \\
\text { içerikli Bis-akril } \\
\text { kompozit rezin }\end{array}$ & $\begin{array}{c}\text { Ivoclar } \\
\text { Vivadent, New } \\
\text { York, USA }\end{array}$ & T48659 & A2 \\
\hline
\end{tabular}

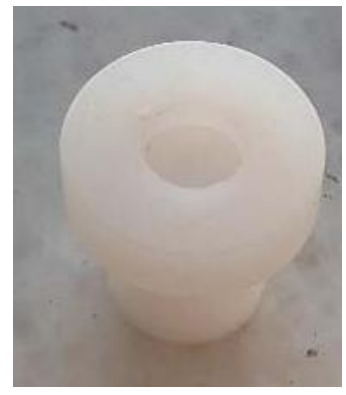

Resim 1. Teflon kalıp. 


\section{Örneklerin hazırlanması}

-Whitepeaks CopraTemp örneklerin hazırlanması:

Özel teflon kalıp aracılığı ile $10 \mathrm{~mm}$ çap ve 3 $\mathrm{mm}$ yükseklikte elde edilen mum örnek CAD/CAM cihazında tarandıktan sonra, laboratuvar ortamında prefabrike bloktan (Whitepeaks, Ivoclar Vivadent, Schaan, Liechtenstein) CAD/CAM cihazı (Yenamak D15, Yenadent Ltd, İstanbul, Türkiye) tarafından frezeleme yoluyla elde edilmiştir.

-Integra örneklerin hazırlanması:

Üretici firmanın önerileri doğrultusunda (2 toz/1 likit) oranında karıştırılan akril hamuru (Integra, Birleşik Grup Dental, Ankara, Türkiye) teflon kalıbın içine yerleştirildikten sonra üzeri siman camı ile kapatıldı. Bu sırada hafif baskı uygulanarak fazla materyalin taşması ve düzgün bir yüzey elde edilmesi sağlandı. Kimyasal polimerizasyonu tamamlanan örnekler kalıptan ayrıldı.

-Triad örneklerin hazırlanması

Teflon kalıplara yerleştirilen malzeme (Triad, Dentsply, York, PA, ABD) siman camı üzerinden LED ışık kaynağı (Bluephase, Ivoclar Vivadent, Schaan, Liechtenstein) ile 30'ar sn alt ve üst yüzeylerden ışınlanarak başlangıç polimerizasyonu sağlandı. Kalıptan ayrılan örnekler polimerizasyon cihazında (TRIAD 2000 Visible Light Curing Unit; Dentsply, York, $A B D) 2 \mathrm{dk}$ süre ile polimerize edildi.

-Systemp.c\&b II örneklerin hazırlanması

Otomatik tabanca sistemi kullanılarak teflon kalıplara yerleştirilen malzeme (Systemp.c\&b II, Ivoclar Vivadent, New York, USA) 4-5 dk beklenerek polimerizasyonu sağlandı. Materyal sertleştikten sonra yüzeyi etil alkol ile silindi.

Tüm örneklerin yüzeyleri su zımparası (800 gren) ile $1 \mathrm{dk}$ boyunca zımparalandıktan sonra etüvde (EN 120, Ankara) $37^{\circ} \mathrm{C}$ deki distile suda 24 saat süre bekletildi. Hazırlanan her bir geçici materyal grubu daha sonra kendi arasında bekletilen sıvı tipine göre 3 alt gruba ayrımıştır (distile su, çay, kahve) $(n=5)$.

Distile su grubu: Bu gruptaki örnekler etüvde (EN 120) $37^{\circ} \mathrm{C}^{\prime}$ deki distile suda 48 saat süre ile bekletilmiştir.

Çay grubu: Bir adet poşet çay (Lipton Yellow Label Tea, Unilever San ve Tic., Ümraniye, İstanbul) $200 \mathrm{ml}$ kaynamış suda $10 \mathrm{dk}$ bekletildikten sonra, çay $37^{\circ} \mathrm{C}$ sıcaklığa gelince etüve (EN 120) konularak örnekler 48 saat süre ile bu sıvıda bekletilmiştir.
Kahve grubu: Bir poşet kahve (2gr) (Nescafe Classic, Nestle Suisse S.A., Vevey, İsviçre) $200 \mathrm{ml}$ kaynamış suda çözündürüldükten sonra, kahve $37^{\circ} \mathrm{C}$ sıcaklığa gelince etüve (EN120) konularak, örnekler 48 saat süre ile bu sıvıda bekletilmiştir. Her 3 sıvıda da örnekler bekletilirken birbiri ile temas etmeyecek şekilde bekletilmiştir. İlgili süre sonunda örnekler sıvıdan çıkarıldıktan sonra distile su ile yıkanmıştır.

Çalışmada kullanılan 48 saatlik bekletme süresinin 2 aylık kullanım süresine denk geldiği belirtilmiştir. $^{8}$

\section{Renk Ölçümü}

Tüm örneklerin renk ölçümleri başlangıçta (örnekler hazırlandıktan 24 saat sonra) ve farklı sıvı ortamlarında (distile su, çay, kahve) 48 saat bekletme sonrasında gerçekleştirilmiştir. Renk ölçümleri beyaz zemin üzerinde, gün ışı̆̆ı altında spektrofotometre cihazı (Vita Easyshade Advance 4.0, Vita Zahnfabrik, Germany) ile gerçekleştirilmiştir. Her bir örneğin başlangıç ve 48 saat sonraki $L$, a, b renk değerleri kaydedildi.

Kırk sekiz saat sonraki renk değişim değerleri $(\Delta \mathrm{E})$ aşağıdaki formü ${ }^{15}$ ile elde edildi:

$$
\begin{aligned}
& \Delta E=\left[\left(L_{s}-L_{b}\right)^{2}+\left(a_{s}-a_{b}\right)^{2}+\left(b_{s}-b_{b}\right)^{2}\right]^{1 / 2} \\
& \text { s: Kırk sekiz saat sonra } \\
& \text { b: başlangıç }
\end{aligned}
$$

\section{Pürüzlülük ölçümü}

Tüm örneklerin pürüzlülük ölçümleri başlangıçta (örnekler hazırlandıktan 24 saat sonra) ve farklı sıvı ortamlarında (distile su, çay, kahve) 48 saat bekletme sonrasında renk ölçümünün hemen arkasından gerçekleştirilmiştir. Örneklerin yüzey pürüzlülük değerleri (Ra; $\mu \mathrm{m})$ yüzey pürüzlülük cihazı (Surftest SJ-201P, Mitutoyo, Japan) ile ölçülmüştür. Pürüzlülük ölçümünde cihaz ölçüm uzunluğu $5,5 \mathrm{~mm}$ ve ölçüm hızı $0,5 \mathrm{~mm} / \mathrm{sn}$ olacak şekilde ayarlanmıştır. Her örneğin 3 farklı bölgesinden ölçüm yapılarak kayıt alınmış ve bu kayıtların ortalaması alınarak her bir örnek için ortalama Ra $(\mu \mathrm{m})$ değeri hesaplanmıştır.

\section{Ístatistiksel analiz}

Tüm örneklerin 48 saat sonraki renk değişim verileri $(\Delta E)$ iki yönlü varyans analizi (ANOVA) ile incelenmiştir.

Yüzey pürüzlülük başlangıç verileri tek yönlü ANOVA ile, 48 saat sonraki pürüzlülük ve pürüzlülük 
fark değişim (sonra-önce) değerleri iki yönlü ANOVA ile analiz edilmiştir. Tüm ANOVA testlerinde çoklu karşılaştırmalar Tukey HSD testi ile incelenmiştir. İlave olarak renk değişim ve pürüzlülük değişim arasındaki ilişki Pearson kolerasyon analizi ile incelenmiştir $(p=0,05)$.

\section{BULGULAR}

Tüm materyallerin 48 saat sonraki renk değişim değerleri $(\Delta \mathrm{E})$ Tablo 2'de verilmiştir. İki yönlü ANOVA sonucuna göre geçici materyallerin 48 saat sonraki renk değişim değerlerini sadece içecek faktörü anlamlı olarak etkilemiştir $(p=0,000)$ (Tablo 3). İçecek faktörü açısından tek yönlü ANOVA yapıldığında, geçici materyal tipine bağı olmadan çayda bekletilen örneklerin renk değişim değerleri distile su ve kahvede bekletilenlere göre anlamlı yüksek iken $(p<0,005)$, distile su ve kahvede bekletilen örnekler arasında istatistiksel olarak anlamlı farklıık bulunamamışıı $(p>0,05)$.

Tablo 2. Kırk sekiz saat sonraki renk değişim değerleri $(\Delta \mathrm{E})$.

\begin{tabular}{cccc}
\hline & \multicolumn{3}{c}{ Ortalama \pm Standart Sapma } \\
\cline { 2 - 4 } Geçici materyal & \multicolumn{3}{c}{ Sıvı tipi } \\
\cline { 2 - 4 } & Distile su & Kahve \\
\hline Whitepeaks CopraTemp & $2,14 \pm 4,14$ & $3,88 \pm 1,55$ & $1,79 \pm 0,86$ \\
Integra & $1,18 \pm 0,69$ & $4,39 \pm 0,26$ & $3,08 \pm 0,41$ \\
Triad & & & \\
& $1,82 \pm 0,48$ & $5,30 \pm 1,91$ & $2,08 \pm 0,84$ \\
Systemp & $0,77 \pm 0,22$ & $3,11 \pm 0,36$ & $3,06 \pm 0,55$ \\
\hline
\end{tabular}

Tablo 3. Kırk sekiz saat sonraki renk değişim değerlerinin $(\Delta \mathrm{E})$ iki yönlü ANOVA sonucu.

\begin{tabular}{lll}
\hline Etki & $\mathrm{F}$ değeri & $\mathrm{P}$ \\
\hline Materyal & 0,743 & 0,532 \\
İçecek & 17,001 & 0,000 \\
MateryalXİçecek & 1,547 & 0,183 \\
\hline
\end{tabular}

Tüm materyallere ait başlangıç ve 48 saat sonraki yüzey pürüzlülük ve pürüzlülük fark değişim değerleri (sonra-önce) Tablo 4'te verilmiştir. Tek yönlü ANOVA'ya göre başlangıç pürüzlülük değerleri açısından tüm materyaller arasında anlamlı farklılık gözlenmiştir $(p=0,000)$ (Tablo 5). Başlangıç yüzey pürüzlülüğü açısından en yüksek pürüzlülük değerini Triad göstermiş, bunu sırası ile yüksekten alçağa doğru Systemp, Whitepeaks CopraTemp ve Integra izlemiştir.

Tablo 4. Pürüzlülük değerleri $\left(R_{a}\right)(\mu m)$.

\begin{tabular}{|c|c|c|c|c|}
\hline \multirow[b]{2}{*}{ Geçici Mat } & \multirow[b]{2}{*}{ İçecek } & \multicolumn{3}{|c|}{ Ortalama \pm Standart Sapma } \\
\hline & & Başlangıç & $\begin{array}{c}48 \text { saat } \\
\text { sonra }\end{array}$ & $\begin{array}{c}\text { Fark (sonra- } \\
\text { önce) }\end{array}$ \\
\hline \multirow{3}{*}{$\begin{array}{l}\text { Whitepeaks } \\
\text { CopraTemp }\end{array}$} & $\begin{array}{c}\text { Distile } \\
\text { su }\end{array}$ & $\begin{array}{c}0,216 \\
\pm 0,016\end{array}$ & $0,218 \pm 0,017$ & $0,002 \pm 0,008$ \\
\hline & Çay & $0,236 \pm 0,020$ & $0,254 \pm 0,011$ & $0,018 \pm 0,013$ \\
\hline & Kahve & $0,218 \pm 0,008$ & $0,252 \pm 0,008$ & $0,034 \pm 0,005$ \\
\hline \multirow{3}{*}{ İntegra } & $\begin{array}{l}\text { Distile } \\
\text { su }\end{array}$ & $0,170 \pm 0,010$ & $0,184 \pm 0,020$ & $0,014 \pm 0,015$ \\
\hline & Çay & $0.188 \pm 0,020$ & $0.216 \pm 0.015$ & $0,028 \pm 0,016$ \\
\hline & Kahve & $0,200 \pm 0,015$ & $0,282 \pm 0,022$ & $0,082 \pm 0,017$ \\
\hline \multirow{3}{*}{ Triad } & $\begin{array}{c}\text { Distile } \\
\text { su }\end{array}$ & $0,458 \pm 0,010$ & $0,472 \pm 0,017$ & $0,014 \pm 0,008$ \\
\hline & Çay & $0,436 \pm 0,015$ & $0,476 \pm 0,021$ & $0,040 \pm 0,012$ \\
\hline & Kahve & $0,446 \pm 0,016$ & $0,526 \pm 0,013$ & $0,080 \pm 0,020$ \\
\hline \multirow{3}{*}{ Systemp.c\&b II } & $\begin{array}{c}\text { Distile } \\
\text { su }\end{array}$ & $0,314 \pm 0,011$ & $0,326 \pm 0,011$ & $0,012 \pm 0,0130$ \\
\hline & Çay & $0,332 \pm 0,014$ & $0,370 \pm 0,015$ & $0,038 \pm 0,008$ \\
\hline & Kahve & $0,328 \pm 0,017$ & $0,380 \pm 0,014$ & $0,052 \pm 0,008$ \\
\hline
\end{tabular}

Hem 48 saat sonraki yüzey pürüzlülük verileri, hem de yüzey pürüzlülük fark değişim (sonra-önce) verilerinin iki yönlü ANOVA analizi sonucuna göre yüzey pürüzlülük değerleri materyal, içecek ve materyalXiçecek faktörlerinden anlamlı olarak etkilenmiştir $(p<0,005)$ (Tablo 5). Kırk sekiz saat sonraki yüzey pürüzlülük değerleri başlangıç yüzey pürüzlülüğünde olduğu gibi en yüksek Triad'da gözlenmiş, bunu yüksekten alçağa doğru sırası ile Systemp, Whitepeaks CopraTemp ve Integra izlemiştir. Whitepeaks CopraTemp ve Integra arasında anlamlı farkllık olmamasına rağmen, diğer materyaller arasında istatistiksel olarak anlamlı farklılık vardır $(p=0,000)$.

Tablo 5. Yüzey pürüzlülük başlangıç, 48 saat sonra ve fark değişim değerlerinin $(R)$ (sonra-önce) $(\mu \mathrm{m})$ ANOVA sonuçları.

\begin{tabular}{|c|c|c|c|c|c|c|}
\hline \multirow{2}{*}{\multicolumn{2}{|c|}{$\begin{array}{c}\begin{array}{c}\text { Tek yönlü } \\
\text { ANOVA }\end{array} \\
\text { Başlangıç } \\
\end{array}$}} & \multirow{3}{*}{ Etki } & \multicolumn{4}{|c|}{ İki yönlü ANOVA } \\
\hline & & & \multicolumn{2}{|c|}{48 saat sonra } & \multicolumn{2}{|c|}{$\begin{array}{l}\text { Fark (sonra- } \\
\text { önce) }\end{array}$} \\
\hline $\mathrm{F}$ & $\mathrm{P}$ & & $\mathrm{F}$ & $P$ & $\mathrm{~F}$ & $P$ \\
\hline \multirow[b]{2}{*}{673,645} & & Materyal & 832,859 & 0,000 & 12,489 & 0,000 \\
\hline & 0,000 & $\begin{array}{c}\text { İçecek } \\
\text { MateryalXİçecek }\end{array}$ & $\begin{array}{c}66,282 \\
6,356\end{array}$ & $\begin{array}{l}0,000 \\
0,000\end{array}$ & $\begin{array}{c}79,478 \\
3,681\end{array}$ & $\begin{array}{l}0,000 \\
0,004 \\
\end{array}$ \\
\hline
\end{tabular}


Yüzey pürüzlülük fark değişim değerleri açısından Systemp, Triad, Integra arasında farklılık bulunmamış ve bu materyaller Whitepeaks CopraTemp materyaline göre daha yüksek pürüzlülük fark değişim değeri göstermiştir $(p<0,01)$.

İçecek tipi açısından değerlendirildiğinde, hem 48 saat sonra hem de yüzey pürüzlülük fark değişim değerleri açısından en yüksek pürüzlülük kahvede, takiben çay ve distile suda bekletilen örneklerde gözlenmiştir. Her üç grup arasında da istatistiksel olarak anlamlı farklılık vardır $(p=0,000)$.

Pearson kolerasyon analizine göre renk değişim ve pürüzlülük değiş̧im değerleri arasında pozitif, ancak anlamılı bir ilişki bulunmamıştır ( $r: 0,201 ; p>0,05)$.

\section{TARTIŞMA}

Yapılan çalışmalarda farklı içeceklerin, ${ }^{8,14}$ farkı içecek ve bekletme süresinin ${ }^{11,12}$ farklı geçici materyallerin renklenmesi üzerindeki etkisi incelenmiştir. Bu çalışmalardan Güler ve ark ${ }^{8}$ farklı içecek tipinin; Güngör ve ark $^{14}$ farklı içecek tipi ve geçici materyal tipinin; diğer araştırmacılar ${ }^{11,12}$ ise farklı içecek tipi ve bekletme süresinin farklı geçici materyallerin renk stabilitesi üzerinde önemli etkisi olduğunu belirtmişlerdir. Güler ve $\operatorname{ark}^{8} 24$ saat bekletme süresi sonunda çay, kahve veya kırmızı şarabın hem bisakril hem de ışıkla polimerize geçici materyaller üzerinde klinik olarak kabul edilemez renk değiş̧imine sebep olduğunu belirtirken, Güngör ve $\operatorname{ark}^{14} 48$ saat bekletme süresi sonunda çay, kahve ve kırmıı şarabın ışıkla polimerize geçici materyaller üzerinde klinik olarak kabul edilemez renk değişimine sebep olduğunu belirtirmişlerdir. Diğer araştırmacılar is $\mathrm{e}^{11,12} 1$ ay bekletme süresi sonunda kabul edilemez renk değişiminin sadece kahvede bekletilen örneklerde olduğunu belirtmişlerdir.

Mevcut çalışmadaki renk değişim analizi sonuçlarına göre tüm materyallerin 48 saat sonraki renk değişim değerleri materyal tipine bağlı olmadan sadece sıvı tipinden anlamlı olarak etkilendiği için birinci hipotez kısmi olarak kabul edilmiştir. Çayda bekletilen örnekler, distile su ve kahvede bekletilenlere göre anlamlı yüksek renk değişim değeri göstermiş $(p<0,005)$ ve tüm geçici materyaller sadece çayda bekletildiğinde klinik olarak kabul edilemez renk değişimi göstermiştir. Diğer çalışmalar ${ }^{8,11,12,14}$ ve mevcut çalışma arasındaki farklılıklar uygulama süresindeki ve test edilen geçici materyallerin tiplerinin farklı olmasından kaynaklanmış olabilir.

Haselton ve ark $^{13}$ farklı geçici materyallerin (metakrilat ve bis-akril esaslı) yüzey pürüzlülüklerini başlangıçta ve farklı sıvılarda (yapay tükrük, yapay tükrük +kahve) bekletme sonrası ölçmüş ve karşılaştırmıştır. Metakrilat rezinlerin başlangıçta bisakril esaslı rezinlere göre daha düzgün yüzey gösterdiği ve farklı Sıvı ortamlarında bekletme sonrası tüm materyallerin yüzey pürüzlülüğünün arttı̆ı̆ belirtilmiştir.

Mevcut çalışmada hem başlangıçta hem de farklı sıvılarda 48 saat bekletme sonrasında metakrilat esaslı geçici materyaller (Integra ve Whitepeaks), Işıkla polimerize (Triad) ve kimyasal polimerize olan geçici materyale (Systemp.c\&b II) göre daha düzgün yüzey göstermiştir. Hem başlangıç hem de 48 saat sonraki yüzey pürüzlülük analiz sonuçları incelendiğinde, her iki durumda da en yüksek pürüzlülük değerini Triad materyali göstermiş, bunu sırası ile Systemp, CAD/CAM ve Integra izlemiştir. Bekletme sonrası tüm geçici materyallerin yüzey pürüzlülük değerleri başlangıç değerleri ile karşılaştırıldığında artmıştır. Bu sonuç Haselton ve ark'nın çalışmasını ${ }^{13}$ sonuçlarını desteklemektedir. Bu durumun metakrilat rezinlerin homojen yapısına ve doldurucu içermemelerine ${ }^{13,16}$ ve sivilarda bekletme sonrası materyalin su emiliminin artmasına bağı olabileceği düşünülmektedir.

Tüm materyallerin başlangıç yüzey pürüzlülük değerleri materyal tipinden anlamlı etkilendiğinden ve tüm materyallerin 48 saat sonraki yüzey pürüzlülük değerleri materyal tipi ve sIVı tipinden anlamlı etkilendiğinden ikinci ve üçüncü hipotez red edilmiştir.

Dental materyallerin yüzey pürüzlülüğü ve renk stabiliteleri arasında ilişki olduğu belirtilmesine rağmen, ${ }^{17}$ çalışmamızda yüzey pürüzlülüğü ve renk stabilitesi arasında pozitif yönlü; ancak anlamlı bir ilişki bulunamamıştır.

$\mathrm{Bu}$ çalışmada farklı polimerizasyon tiplerine sahip klinik kullanımda sıklıkla tercih edilen 4 farklı geçici materyalin renk ve yüzey pürüzlülük parametreleri incelenmiştir. Sabit protetik tedavide kullanılan geçicilerin klinik başarısında her iki parametre de önemli rol oynayan faktörler olduğu için bu çalışmada incelenmiştir. Tüm materyaller Güler ve ark'nın çalışması $^{8}$ referans alınarak 2 aylık klinik kullanıma denk geldiği belirtilen 48 saat süre ile farklı 
Sıvılarda bekletilmiştir ve tüm geçici materyallerin 48 saat sonraki renk değişim değerleri hesaplanmıştır. Yapılan çalışmalarda ${ }^{12,18-20}$ renk değişim değerinin $(\Delta \mathrm{E})^{\prime}$ nin 3,3' ün aşağısında olmasının renk değişiminin klinik olarak kabul edilebilir olarak belirlenebileceği belirtildiği için; çalışmada bu parametre baz alınarak renk değişim değerleri buna göre değerlendirilmiştir. İlave olarak tüm materyallerin başlangıç, 48 saat sonraki yüzey pürüzlülük değerlerinin yanı sıra yüzey pürüzlülük fark değişim değerleri de incelenerek her bir materyalin farklı sürelerde yüzey pürüzlülük değerleri hem kendi içinde hem de birbirleri ile karşılaştırılmış ve sıvı ortamda bekletmeye dirençli olan geçici materyaller de incelenmiştir.

$\mathrm{Bu}$ çalışmanın bazı limitasyonları vardır. Vita Easyshade cihazı ile elde edilen renk değerleri sınırlı kapasiteye sahip olduğundan, bu sonuçların gelişmiş renk ölçüm cihazları ile örtüşmesi gerekmektedir. Çalışmanın diğer bir limitasyonu da tüm materyallerin farklı sıvılarda sadece 48 saat bekletme sonrası renk değişim değerleri karşılaştırılmıştır. Gelecekteki araştırmalarda farklı sürelerin (kısa ve uzun dönem), farklı asidik veya bazik içeceklerin bu materyallerin renk stabilite ve yüzey pürüzlülüğü üzerindeki etkilerinin incelenmesi gerekmektedir.

\section{SONUÇ}

1. Kısa dönem değerlendirme sonunda geçici materyallerin renk değişiminin sadece sıvı tipinden; pürüzlülük değişiminin ise materyal tipi ve sIVı tipinden anlamlı etkilendiği bulunmuştur.

2. Tüm materyallerin sadece çayda bekletilen örneklerinin 48 saat sonraki renk değişim değerleri klinik olarak kabul edilemez bulunurken $(\Delta \mathrm{E}>3,3)$; distile su veya kahvede bekletilen örneklerin 48 saat sonraki renk değişimleri klinik olarak kabul edilebilir bulunmuştur $(\Delta \mathrm{E}<3,3)$.

3. Kısa dönem değerlendirme sonunda geçici materyallerin renk ve yüzey pürüzlülük değişim sonuçları beraber değerlendirildiğinde CAD/CAM sistemi ile üretilen geçici materyal (Whitepeaks CopraTemp) diğer geçici materyallere göre tercih edilebilir.

4. Klinisyenler piyasada mevcut olan birçok geçici materyali seçerken, geçici materyallerin optik özellik ve yüzey pürüzlülüğü gibi özelliklerini de göz önünde bulundurmalıdırlar.
Gülce Subaşı: ORCID ID: 0000-0002-2510-9745

Necla Demir: ORCID ID: 0000-0003-0927-6962

Muhammet Karcl: ORCID ID: 0000-0002-7101-822X

Mehtap Bozkurt: ORCID ID: 0000-0001-5933-9146

\section{KAYNAKLAR}

1. Gough M. A review of temporary crowns and bridges. Dent Update 1994;21:203-7.

2. Kim SH, Watts DC. Exotherm behavior of the polymer-based provisional crown and fixed partial denture materials. Dent Mater 2004;20:383-7.

3. Christensen GJ. The fastest and best provisional restorations. J Am Dent Assoc 2003;134:637-9.

4. Poonacha V, Poonacha S, Salagundi B, Rupesh PL, Raghavan R. In vitro comparision of flexural strength and elastic modulus of three provisional crown materials used in fixed prosthodontics. J Clin Exp Dent 2013;5:e212-7.

5. Wassell RW, St George G, Ingledew RP, Steele JG. Crowns and other extra-coronal restorations: provisional restorations. Br Dent J 2002;192:61922,625-30.

6. Alt $V$, Hannig $M$, Wöstmann $B$, Balkenhol $M$. Fracture strength of temporary fixed partial dentures: CAD/CAM versus directly fabricated restorations. Dent Mater 2011;27:339-47.

7. Karaokutan I, Sayin G, Kara O. In vitro study of fracture strength of provisional crown materials. J Adv Prosthodont 2015;7:27-31.

8. Guler AU, Yilmaz F, Kulunk T, Guler E, Kurt S. Effects of different drinks on stainability of resin composite provisional restorative materials. J Prosthetic Dent 2005;94:118-24.

9. Sham AS, Chu FC, Chai J, Chow TW. Color stability of provisional prosthodontic materials. J Prosthet Dent 2004;91:447-52.

10. Doray PG, Li D, Powers JM. Color stability of provisional restorative materials after accelerated aging. J Prosthodont 2001;10:212-6.

11. Kohli S, Bhatia S, Sexana K, Kalsi R, Rajeshwari K, Arora M. Discolouration of polymethyl methacrylate versus bis-acrylic based provisional crown and bridge dental resins: Effect of storage media and duration. Ann Med Health Sci Res 2017;7:195-9.

12. Yannikakis SA, Zissis AJ, Polyzois GL, Caroni C. Color stability of provisional resin restorative materials. J Prosthet Dent 1998;80:533-9. 
13. Haselton DR, Diaz-Arnold AM, Dawson DV. Effect of storage solution on surface roughness of provisional crown and fixed partial denture materials. J Prosthodont 2004;13:227-32.

14. Güngör MB, Nemli SK, Bal BT, Doğan A. Farklı içeceklerde bekletilen geçici restorasyon materyallerinin renk stabilitelerinin karşılaştırılması. Acta Odontol Turc 2016;33:80-5.

15. Nasim I, Neelakantan P, Sujeer P, Subbarao CV. Color stability of microfilled, microhybrid and nanocomposite resin. An in vitro study. J Dent 2010;38:e137-42.

16. Borchers L, Tavassol F, Tschernitschek H. Surface quality achieved by polishing and by varnishing of temporary crown and fixed partial denture resins. J Prosthet Dent 1999;82:550-6.

17. Rutkunas V, Sabaliauskas V, Mizutani H. Effects of different food colorants and polishing techniques on color stability of provisional prosthetic materials. Dent Mater J 2010;29:167-76.

18. Johnston WM, Kao EC. Assessment of appearance match by visual observation and clinical colorimetry. J Dent Res 1989;68:819-22.

19. Çelik N, Sağsöz Ö, Gündoğdu M. Farklı içeceklerin posterior kompozitlerin renk değişikliği ve yüzey pürüzlülüğü üzerine etkisinin değerlendirilmesi. Atatürk Üniv Diş Hek Fak Derg 2017;27:27-33.

20. Güler E, Gönülol N, Yücel AÇ, Yilmaz F, Ersöz E. Farklı içeceklerde bekletilen kompozit rezinlerin renk stabilitelerinin karşılaştırılması. Atatürk Üniv Diş Hek Fak Derg 2013;21:24-9.

\author{
Yazışma Adresi \\ Dr. Öğr. Üyesi M.Gülce Subaşı \\ Kütahya Sağlık Bilimleri Üniversitesi, \\ Protetik Diş Tedavisi ABD, Kütahya \\ Tel: 02742652269/1324 \\ e-mail: gulce2subasi@yahoo.co.uk
}

